\title{
Thermal Ablation for Benign Thyroid Nodules: Radiofrequency and Laser
}

\author{
Jung Hwan Baek, MD ${ }^{1}$, Jeong Hyun Lee, MD ${ }^{1}$, Roberto Valcavi, MD, FACE², Claudio M. Pacella, MD², \\ Hyunchul Rhim, $M D^{4}$, Dong Gyu Na, $M D^{5}$ \\ ${ }^{1}$ Department of Radiology and Research Institute of Radiology, University of Ulsan College of Medicine, Asan Medical Center, Seoul 138-736, \\ Korea; ${ }^{2}$ Endocrinology Division \& Thyroid Disease Center, Arcispedale Santa Maria Nuova 42123, Reggio Emilia, Italy; ${ }^{3}$ Diagnostic Imaging and \\ Interventional Radiology Department, Ospedale Regina Apostolorum 00041, Albano Laziale-Rome, Italy; ${ }^{4}$ Department of Radiology and Center for \\ Imaging Science, Samsung Medical Center, Sungkyunkwan University School of Medicine, Seoul 135-710, Korea; ${ }^{5}$ Department of Radiology, Human \\ Medical Imaging and Intervention Center, Seoul 137-902, Korea
}

Although ethanol ablation has been successfully used to treat cystic thyroid nodules, this procedure is less effective when the thyroid nodules are solid. Radiofrequency (RF) ablation, a newer procedure used to treat malignant liver tumors, has been valuable in the treatment of benign thyroid nodules regardless of the extent of the solid component. This article reviews the basic physics, techniques, applications, results, and complications of thyroid RF ablation, in comparison to laser ablation.

Index terms: Radiofrequency ablation; Thyroid nodule; Ultrasonography; Ethanol ablation; Laser ablation

\section{INTRODUCTION}

Thyroid nodules have been found by palpation in 4-8\% of adults, by ultrasonography (US) in $10-41 \%$, and by pathologic examination at autopsy in $50 \%(1,2)$. Most thyroid nodules are benign but some require treatment for cosmetic reasons or because of subjective symptoms (3). Surgery and treatment with levothyroxine have been used to treat benign thyroid nodules. Although surgery is curative, surgery has several drawbacks (4), and the

Received November 12, 2010; accepted after revision May 23, 2011.

Corresponding author: Jung Hwan Baek, MD, Department of Radiology and Research Institute of Radiology, University of Ulsan College of Medicine, Asan Medical Center, 86 Asanbyeongwon-gil, Songpa-gu, Seoul 138-736, Korea.

- Tel: (822) 3010-4348 - Fax: (822) 476-0090

- E-mail: radbaek@naver.com

This is an 0pen Access article distributed under the terms of the Creative Commons Attribution Non-Commercial License (http://creativecommons.org/licenses/by-nc/3.0) which permits unrestricted non-commercial use, distribution, and reproduction in any medium, provided the original work is properly cited. efficacy of thyroid hormone-suppressive therapy has not yet been determined (5). Therefore, non-surgical, minimally invasive modalities, including ethanol ablation (EA) and percutaneous laser ablation (PLA), have been used to treat thyroid nodules and both methods yield good results (3, $6-10)$. Although EA is very effective when used to treat cystic thyroid nodules $(8,10-13)$, EA is less effective in solid nodules $(14,15)$. Laser ablation (LA) is a thermal ablation method and is therefore considered to be an optimal therapeutic option for treatment of solid thyroid nodules $(3,6,7,9)$.

Radiofrequency (RF) ablation is a minimally invasive technique that has been used to treat various malignant tumors, especially those of the liver (16-21). In pigs, RF ablation of normal thyroid tissue causes necrosis (22). More recently, RF ablation has been reported to be both effective and safe when used to treat either benign thyroid nodules ( 2 , 15, 23-29) or recurrent thyroid cancer $(30,31)$. In Korea, $\mathrm{RF}$ ablation has been used to treat benign cold $(2,15,24)$ and autonomously functional thyroid nodules (AFTNs) (23, 25). The results have been promising, and no significant 
complications were evident. This review article thus offers information on the basic physics, devices and techniques that have been especially designed to optimize thyroid RF ablation as well as the clinical results, complications, and the technical tips to avoid complications. Finally comparison data of RF ablation and LA were discussed.

\section{Radiofrequency Ablation}

\section{Principles of Radiofrequency Ablation}

Basically, the term RF refers to an alternating electric current oscillating between 200 and $1200 \mathrm{kHz}$ (21). Application of RF power to tissue agitates tissue ions as they attempt to follow the changes in direction of the alternating current. Such agitation creates frictional heat around the electrode (Fig. 1). Although this heat creates immediate damage to tumor tissue, the damage is significant only in regions very close to (thus, within a few $\mathrm{mm}$ of) the electrode. Simultaneously, tumor tissue more remote from the electrode is heated slowly, via thermal conduction from the hot region adjacent to the electrode $(17,21,32)$ (Fig. 2).

The nature of thermal damage caused by RF ablation is dependent on both the tissue temperature achieved and the duration of heating. Elevation of tissue temperature, to $40^{\circ} \mathrm{C}$, does not induce tissue damage. Tissue temperatures between $42-45^{\circ} \mathrm{C}$, formally termed hyperthermia, cause tissue cells to become more susceptible to damage when exposed to chemotherapeutic agents and/or irradiation. Irreversible cellular damage occurs when temperatures

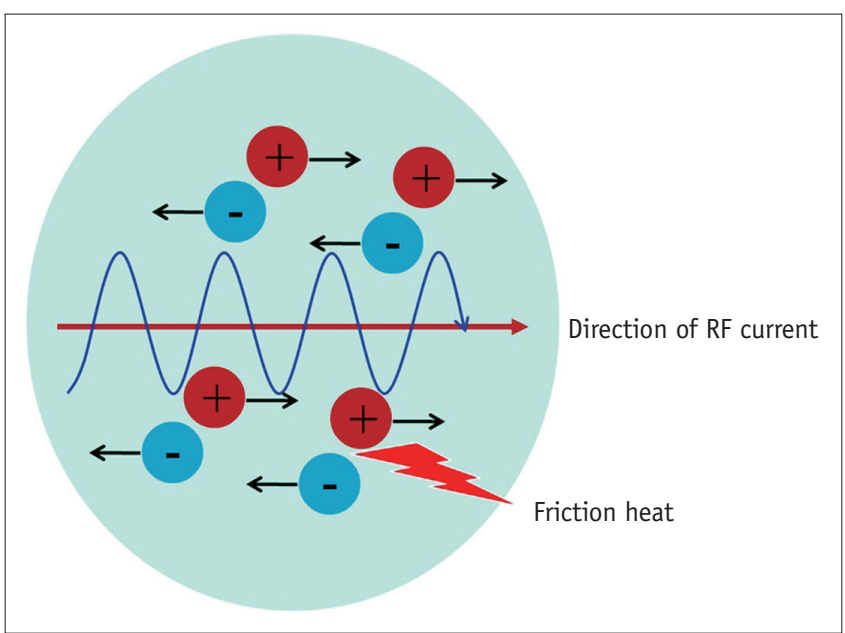

Fig. 1. Ionic agitation and formation of frictional heat. Tissue ions are agitated by application of alternating electric current. Ionic agitation results in ion friction, which in turn causes heat production. $\mathrm{RF}=$ radiofrequency . are increased to $46^{\circ} \mathrm{C}$ for $60 \mathrm{~min}$, or to $50-52^{\circ} \mathrm{C}$ for 4-6 min. Near-immediate tissue coagulation is induced at temperatures between $60-100^{\circ} \mathrm{C}$, but temperatures greater than $100-110^{\circ} \mathrm{C}$ result in tissue vaporization and carbonization $(17,21,33)$.

In a liver malignancy, adequate tumor destruction requires exposure of the entire tumor tissue to cytotoxic temperatures, as well as the exposure of a sphere measuring 0.5 to $1.0 \mathrm{~cm}$ greater in diameter than the tumor containing surrounding normal tissue, to eliminate microscopic tumor foci. Thus, an objective of RF ablation is to achieve and maintain a temperature of $50-100^{\circ} \mathrm{C}$ throughout the entire target volume for at least 4-6 minutes. Adequate ablation of tumor tissue remote from the electrode is achieved more slowly by conduction of heat, increasing the duration of RF ablation to 10-30 minutes $(17,21,32,33)$.

Several factors may reduce the efficacy of RF ablation (17, $21,33)$. The first parameter is temperature. Vaporization and carbonization retard optimal ablation. When tissue vaporization occurs, a large amount of gas is formed. Gas formed around the electrode acts as an insulator, preventing the production and spread of heat. A second factor is the heterogeneous nature of target tissue, such as fibrosis or calcification. Tissue variation can alter electrical and thermal conductance. A third factor is blood flow; this results in perfusion-mediated tissue cooling and reduces the extent of thermal ablation.

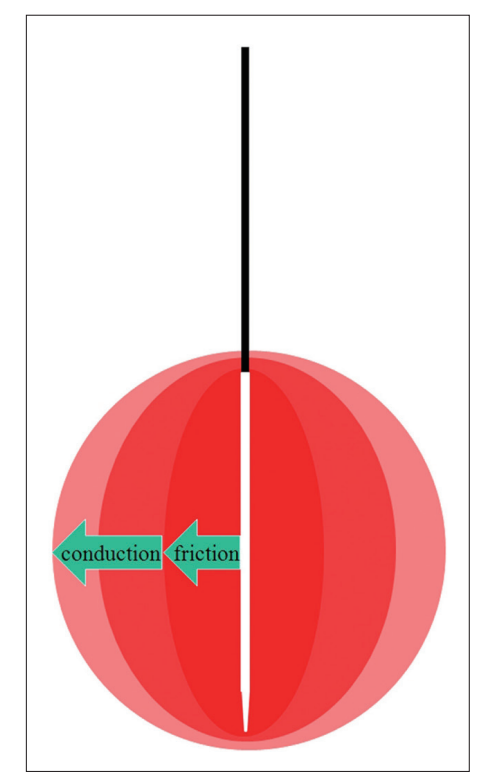

Fig. 2. Heat propagation through target tumor. Immediate tissue coagulation necrosis is achieved by frictional heat generated in vicinity of electrode, but electrode-remote tumor tissue is ablated more slowly, via conductive heat. 


\section{Inclusion Criteria and Patient Preparation}

Radiofrequency ablation of benign thyroid nodules has been used in patients with subjective symptoms and/or cosmetic problems $(2,26,28,29)$ and in patients with AFTN $(23,25-28)$. To exclude malignant thyroid nodules and follicular neoplasms, the investigators of the Korean Society of Thyroid Radiology (34) have recommended that the nodules to be treated should be confirmed as benign lesions using two separate US-guided fine needle aspirations (FNA), and that nodules showing malignant features on US be excluded from RF ablation $(35,36)$.

US, US-guided FNA, and appropriate laboratory tests should be performed before ablation, and all of clinical status including cosmetic and symptomatic problems should be formally recorded (24). Symptomatic concerns are selfreported by patients using a $10-\mathrm{cm}$ visual analog scale. Cosmetic problems are divided into four categories by the physician ( 1 , no palpable mass; 2 , no cosmetic problem but a palpable mass is present; 3 , cosmetic problem on swallowing only; and 4, a readily observable cosmetic problem).

The size, characteristics, proportion of solid component, and internal vascularity of each nodule are evaluated. Three orthogonal nodule diameters, including the largest diameter, are measured by US to assess nodule volume using the equation $V=\pi a b c / 6$, where $V$ is the volume, $a$ is the largest diameter, and $b$ and $c$ are the other two perpendicular diameters (2). Laboratory tests usually include CBC, a blood coagulation battery, and measurements of thyrotrophin (TSH), thyroid hormones, and thyroid auto-antibodies. A ${ }^{99 \mathrm{~m}}$ Tc pertechnetate scintigraphy can be used to differentiate cold nodules from AFTNs, especially in patients showing decreased serum thyrotrophin concentrations.

\section{Devices and Procedures}

\section{Devices for thyroid radiofrequency ablation}

Unlike the liver tumors, in which RF ablation is most commonly used, thyroid nodules have different circumstances (Table 1). In contrast to liver, the thyroid gland is relatively small, whereas thyroid nodules are relatively large and spherical in shape with almost no safety margins. Therefore, new devices and techniques have been developed for thyroid RF ablation. Two types of electrodes have been used for thyroid RF ablation; these are straight internally cooled electrodes and multi-tined expandable electrodes $(2,15,24-26,28,29)$. A straight internally cooled electrode (17-gauge, $15 \mathrm{~cm}$ in length, with a $1-\mathrm{cm}$ active tip) has been used in Korea $(2,15,24,25,29)$, whereas a multi-tined expandable electrode (14-gauge, 10 $\mathrm{cm}$ in length, with 4-9 hooks expandable to $3.5-4.0 \mathrm{~cm}$ ) has been employed in Italy $(26,28)$. A modified, straight internally cooled electrode was developed in Korea (25). This modified electrode is short $(7 \mathrm{~cm})$ to permit easy control; thin, (18-gauge) to minimize injury to the normal thyroid gland; and can be used with active tips of various sizes $(0.5,0.7,1.0$, or $1.5 \mathrm{~cm})$.

\section{Procedures including the "trans-isthmic approach method" and the "moving shot technique"}

Before each procedure, a patient is placed in the supine position with mild neck extension (Fig. 3). Two grounding pads are firmly attached to both thighs. Most operators use a local anesthetic during a procedure $(2,23,24,28$, 29); although one group routinely infuses Ketorolac to prevent pain (26). The approaches utilized to date include the cranio-caudal approach along the greatest axis and the trans-isthmic approach along the short axis of the nodule (Fig. 4).

For the cranio-caudal approach, the operator inserts the electrode tip along the long axis of the nodule $(26,29)$. To avoid overheating of surrounding critical structures, the operator maintains the prong tips at least $10 \mathrm{~mm}$ from the thyroid capsule and at least 5-6 $\mathrm{mm}$ from the margin of the nodule. The nine prong tips are held at least $15 \mathrm{~mm}$ away from surrounding heat-sensitive cervical structures. During ablation, the temperature at the tip of the prongs reaches a maximum of $95-105^{\circ} \mathrm{C}$, and is maintained for 5-8 minutes.

Table 1. Differences between Thyroid Gland and Liver

\begin{tabular}{llll}
\hline Difference & Thyroid gland & Liver & Solution \\
\hline Organ size & Small & Large & Compartmentalization \\
\hline Tumor size & Large & Large & Conceptual ablating unit \\
\hline Tumor shape & Ellipsoid & Round & Moving shot technique \\
Safety margin & Not sufficient & Sufficient & Unit-by-unit ablation \\
Depth of organ & Superficial & Deep & Use of short and thin electrode \\
\hline
\end{tabular}




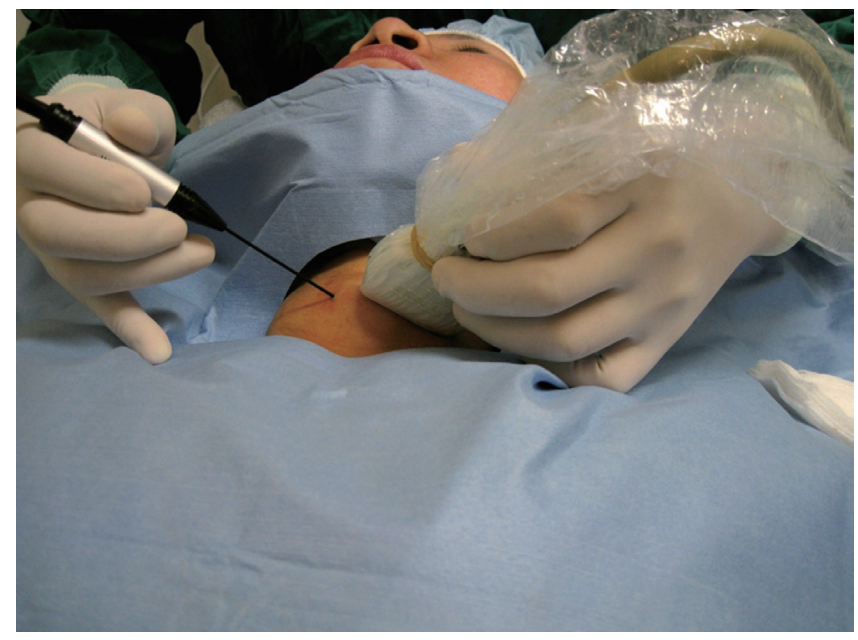

Fig. 3. Positions of operator and patient. Patient is placed in supine position with mild neck extension, and operator stands close to patient's head. Left hand of operator holds US probe and right hand of electrode.

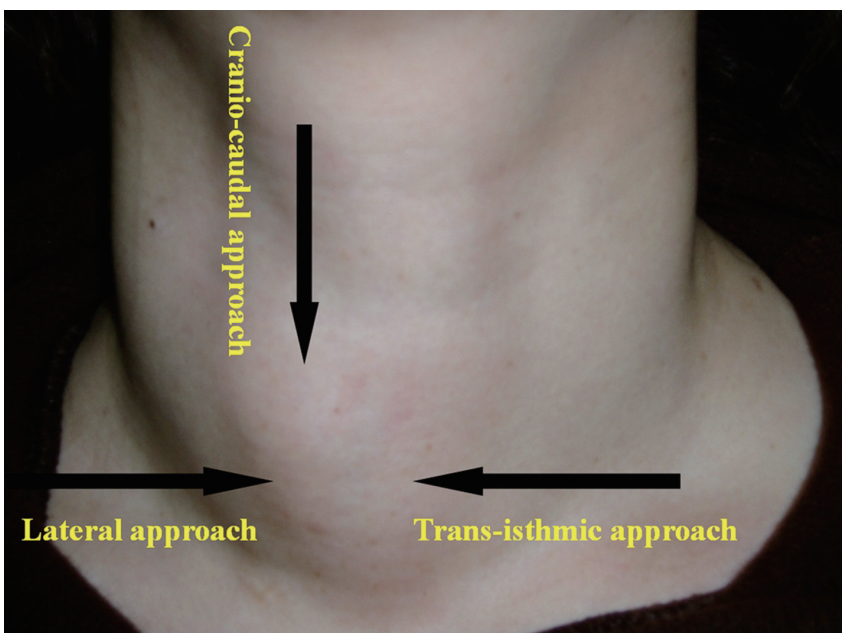

Fig. 4. Three-method approach method employing electrode.

Trans-isthmic approach via short axis of thyroid nodule (from medial to lateral aspect) is used in Korea. When vessels appear to be prominent on trans-isthmic approach route, lateral approach may prevent vessel injury. Cranio-caudal (longitudinal) approach, through axis of thyroid nodule, has been used in Italy for both radiofrequency ablation and percutaneous laser ablation.

Another approach, the trans-isthmic approach, has been used for both RF ablation and EA $(2,11,15,23-25)$. With this method, the electrode is inserted from the medial (isthmus) to the lateral aspect of a targeted nodule, and RF ablation proceeds via a transverse US view (Figs. 4, 5). This method has several advantages compared to the cranio-caudal approach. First, the entire length of the electrode can be visualized on the transverse US view. The second advantage is minimal exposure to the heat of the danger triangle (Fig. 6), which includes the recurrent laryngeal nerve and/or esophagus. During follow-up, an

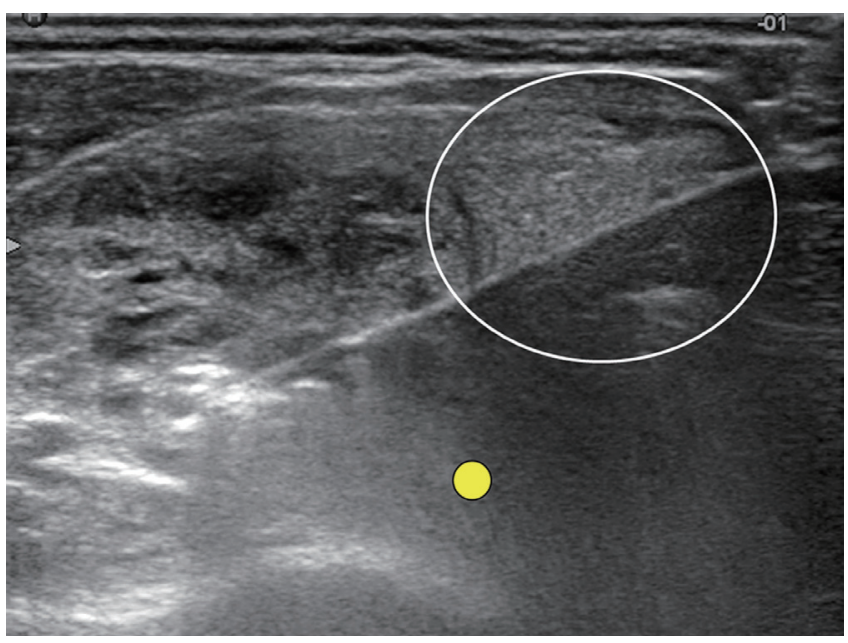

Fig. 5. US image showing trans-isthmic approach. This transverse US image shows electrode in its entirety, thyroid nodule, and possible location of recurrent laryngeal nerve (small yellow circle). Electrode passes through volume of thyroid parenchyma (white circle) adequate to prevent electrode movement.

ablated thyroid nodule is found to decrease in size and to gradually move farther away from critical structures, allowing any undertreated nodule area to receive additional RF ablation (Fig. 6). The third advantage of this approach is that the electrode passes through a sufficient amount of thyroid parenchyma. It prevents a change in the position of the electrode tip during swallowing or talking, as well as preventing leakage of hot ablated fluid outside the thyroid gland. If large numbers of vessels are located in the isthmus, the lateral approach can be used to prevent hemorrhage (Fig. 4).

Baek et al. (24) have proposed a moving shot technique for thyroid nodules $(2,15,23-25)$, in lieu of the fixed electrode technique, which has been used to treat liver tumors $(17,18,21,33)$. In the latter technique, the electrode is fixed in position during ablation, resulting in a round ablation zone. As thyroid nodules are usually ellipsoid in shape, prolonged fixation of the electrode is dangerous to surrounding critical structures (Table 1). Baek et al. (24) have suggested to divide thyroid nodules into multiple small conceptual ablation units, and perform RF ablation unit-by-unit, by moving the electrode. The conceptual units are smaller at the periphery of the nodule and large in the center of the nodule or in regions remote from critical structures. Initially, the electrode tip is positioned in the deepest, most remote, portion of the nodule to enable the tip to be easily monitored in the absence of any disturbance caused by microbubbles (Fig. 7A). Ablation is commenced with $30 \mathrm{~W}$ (1-cm active tip) or $50 \mathrm{~W}(1.5-\mathrm{cm}$ 


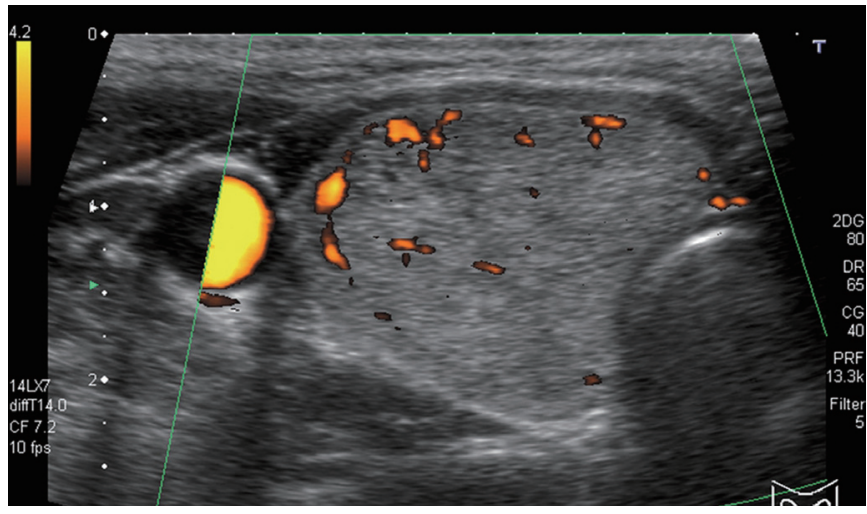

A

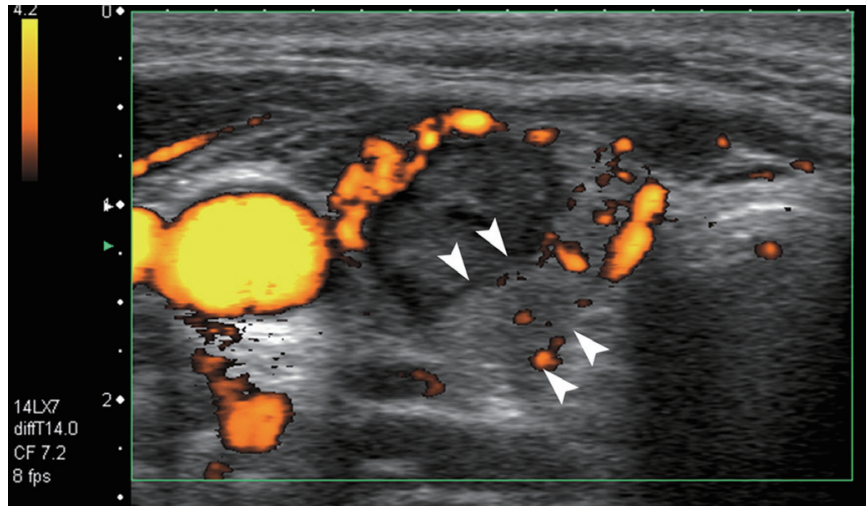

C

active tip) of RF power. When a transient echogenic area appears at the targeted unit, RF power is decreased, and the electrode tip is moved to an untreated area. The electrode is continuously moved both backward and in the superficial direction within the thyroid nodule (Fig. 7). The extent of the ablated area is determined by echogenic changes around the electrode. If a transient hyperechoic zone does not form at the electrode tip within 5-10 seconds, RF power is increased in $10 \mathrm{~W}$ increments to a maximum of 100-110 W. If a patient cannot tolerate the pain associated with ablation, the power is reduced or turned off for several seconds. To treat predominantly cystic thyroid nodules, we usually first aspirate all cystic fluid and next perform an RF ablation. The RF ablation is terminated when all conceptual units of the targeted nodule have become transient hyperechoic zones. However, some regions of each thyroid nodule, including those close to critical structures such as the recurrent laryngeal nerve and esophagus, may remain undertreated.

Operators must monitor any adverse events that occur during and immediately after a procedure. The patient is observed for 1-2 hours in hospital with mild compression of the neck $(2,28)$. Patients who complain of severe neck pain

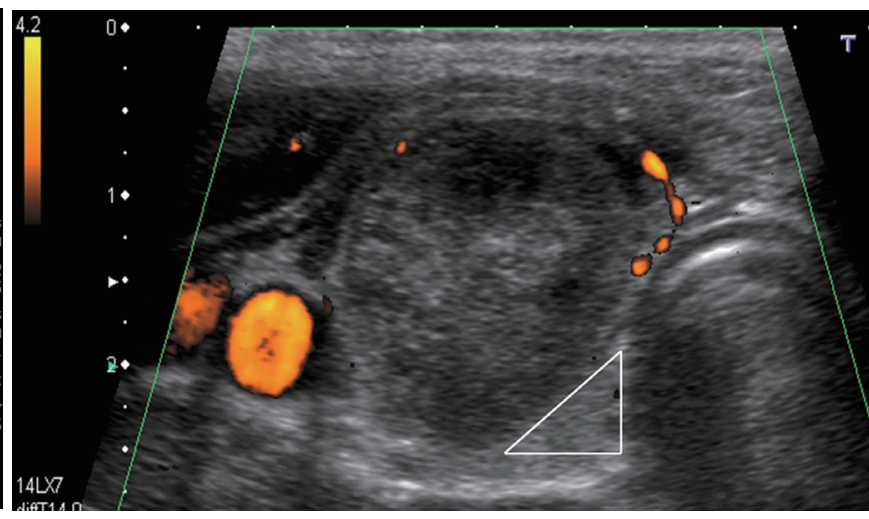

B

Fig. 6. US images showing danger triangle.

A. Transverse image obtained before ablation, in which right thyroid nodule fills entire right thyroid gland and lies close to trachea and recurrent laryngeal nerve. B. Transverse US image taken immediately after ablation, demonstrating less-than-adequate treatment of danger triangle (white triangle), because recurrent laryngeal nerve is located in danger triangle. C. Transverse US image taken one month after ablation, showing that undertreated portion indicated by arrowheads is now apart from recurrent laryngeal nerve and trachea, thus allowing undertreated portion to be safely ablated.

or discomfort usually receive an oral or IV painkiller.

\section{Follow-Up Evaluation}

Follow-up US examinations at 1, 3, 6, and 12 months, and every 6-12 months were routinely performed $(2,28)$. Changes in size, echogenicity, and intranodular vascularity are all evaluated by US. Reduction in volume is determined by US imaging and is calculated using the equation: volume reduction $(\%)=([$ initial volume $(\mathrm{mL})$ - final volume $(\mathrm{mL})]$ $x$ 100)/initial volume (mL) (2). Laboratory tests should be performed immediately on samples from patients who complain of symptoms suggesting any thyroid function abnormality. Complications arising after a procedure are evaluated by analysis of clinical signs and symptoms.

The echogenicity of a nodule would be lower than noted before ablation, and intra-nodular vascularity should disappear in regions receiving complete ablation (2) (Fig. 8). Additional ablation should be performed if a viable portion of the nodule (i.e., showing the same echogenicity as the index nodule and the presence of intra-nodular vascularity) remains on follow-up US, or if a patient complains of incompletely resolved clinical problems, including cosmetic and symptomatic issues $(2,26)$. Although no guidelines are 

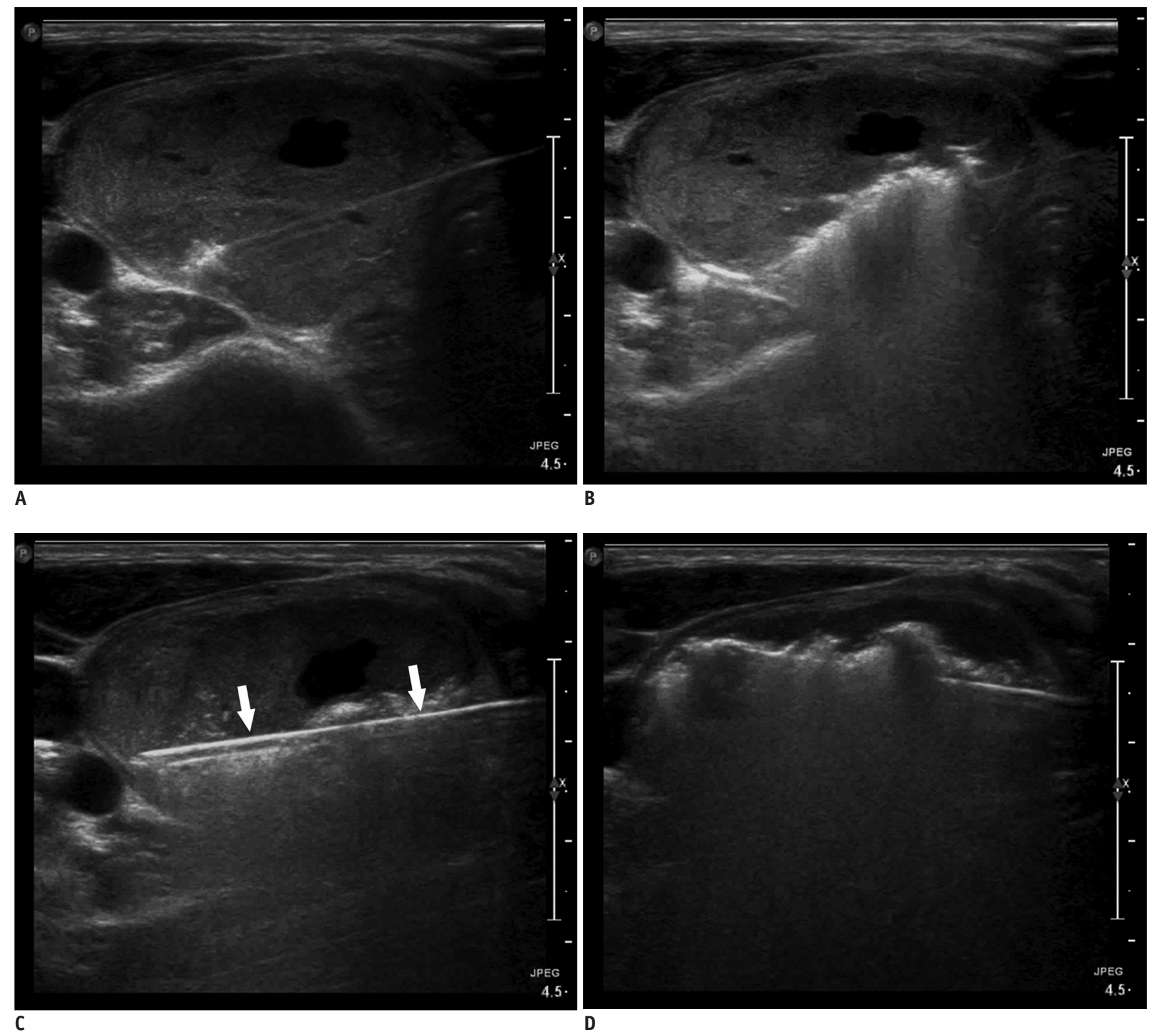

Fig. 7. Sequential US images of moving shot technique showing complete ablation of nodule margins.

A, B. Transverse US images showing initial placement of electrode at periphery of deep and remote portion of target nodule; ablation area was small at periphery and large in central safe area. C, D. Transverse US images showing re-location of electrode in untreated area. Electrode was continuously moved backward and in superficial direction within thyroid nodule. Entire length of electrode was always well demarcated (arrows).

available to identify a time when follow-up US examinations should cease, additional routine US examination is not regarded to be necessary when treated nodule disappeared completely or remains as a small scar like lesion.

\section{Clinical Results}

The results of RF ablation are evaluated by change in nodule volume and improvement in clinical problems, including pressure symptoms and cosmetic issues. The reduction in nodule volume after RF ablation has been found to range from $33-58 \%$ at one month and from 51 -
$85 \%$ at six months $(2,15,24-26,28,29)$ (Table 2$)$. The greatest volume reduction is usually observed within the first month after RF ablation, followed by a more gradual decrease $(2,28)$. The efficacy of RF ablation in treatment of benign, predominantly solid, thyroid nodules has been proven in prospective randomized trials that compared the use of RF ablation with conservative treatment (24).

The first report on the use of RF ablation demonstrated a reduction of nodule volume and improvement of nodulerelated symptoms (29). The results of this study was confirmed by Jeong et al. (2) in a large series volume 

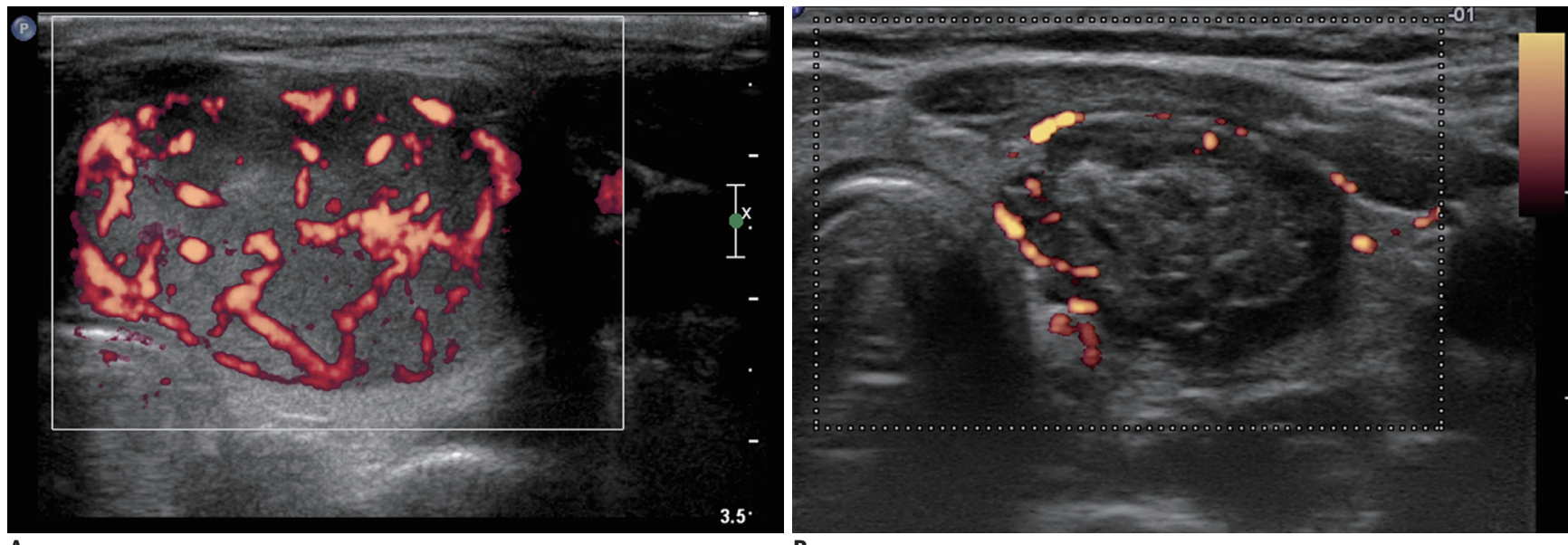

A B

Fig. 8. Transverse US images of well-ablated thyroid nodule, before (A) and 12 months after (B) radiofrequency ablation, showing size reduction, decreased echogenicity, and lack of internal vascularity.

Table 2. Basic Characteristics and Treatment Results of Patients Undergoing Radiofrequency Ablation of Thyroid Nodules

\begin{tabular}{|c|c|c|c|c|c|c|c|}
\hline & $\begin{array}{l}\text { Kim et al., } \\
2006 \text { (29) }\end{array}$ & $\begin{array}{l}\text { Jeong et al., } \\
2008 \text { (2) }\end{array}$ & $\begin{array}{c}\text { Deandrea } \\
\text { et al., } \\
2008(26)\end{array}$ & $\begin{array}{l}\text { Spiezia et al., } \\
2009 \text { (28) }\end{array}$ & $\begin{array}{l}\text { Baek et al., } \\
2009 \text { (25) }\end{array}$ & $\begin{array}{l}\text { Baek et al., } \\
2010 \text { (24) }\end{array}$ & $\begin{array}{l}\text { Lee et al., } \\
2010 \text { (15) }\end{array}$ \\
\hline Number of patients & 35 & 302 & 33 & 94 & 9 & 15 & 27 \\
\hline Number of nodules & 30 & 236 & 31 & 94 & 9 & 15 & 27 \\
\hline Nodule type & Cold & Cold & Cold + AFTN & Cold + AFTN & AFTN & Cold & Cold \\
\hline Solid component (\%) & $0-100$ & $0-100$ & $>30$ & $>30$ & $60-100$ & $>50$ & $10-50$ \\
\hline $\begin{array}{l}\text { Follow-up period } \\
\text { (months) }\end{array}$ & $1-18$ & $1-41$ & 6 & $12-24$ & $6-17$ & $6-8$ & $6-38$ \\
\hline V initial (mL) & 6.3 & 6.13 & 27.7 & 24.5 & 15.0 & 7.5 & 14.0 \\
\hline VR1 (\%) & 47 & 58 & 33 & 54 & 36 & 49 & - \\
\hline VR6 (\%) & 64 & 85 & 51 & - & 71 & 80 & 92 \\
\hline VRlast (\%) & - & 84 & - & 79 & 75 & - & 97 \\
\hline Session (mean) & 1 & $1-6(1.4)$ & 1 & $1-3(1.4)$ & $1-4(2.2)$ & 1 & $1-4(1.6)$ \\
\hline Electrode type & $\begin{array}{l}\text { Internally } \\
\text { cooled }\end{array}$ & $\begin{array}{l}\text { Internally } \\
\text { cooled }\end{array}$ & $\begin{array}{l}\text { Multitined } \\
\text { expandable }\end{array}$ & $\begin{array}{l}\text { Multitined } \\
\text { expandable }\end{array}$ & $\begin{array}{l}\text { Internally } \\
\text { cooled }\end{array}$ & $\begin{array}{l}\text { Internally } \\
\text { cooled }\end{array}$ & $\begin{array}{l}\text { Internally } \\
\text { cooled }\end{array}$ \\
\hline
\end{tabular}

Note. - AFTN $=$ autonomously functioning thyroid nodule, $V=$ volume, $V R=$ volume reduction

reduction at six months after ablation, which found that about $85 \%$ and $28 \%$ of index nodules disappeared on follow-up US.

A single session of RF ablation also showed efficacy in both cold and AFTNs (26). However, volume reductions after RF ablation were less than noted in other reports (2, $25,28,29)$, which may be attributable to the large nodule volume and the use of only a single session of RF ablation. RF ablation is also safe and effective in elderly patients who are poor candidates for surgery (28). RF ablation has been reported to be effective in patients with AFTN, thereby reducing the volume of treated nodules, improving nodule- related symptoms and cosmetic problems, and improving abnormal thyroid function $(23,25)$. Hyperthyroid patients with AFTN required reduced or no methimazole therapy at the end of follow-up (28). RF ablation has also been useful to treat patients who showed incompletely resolved clinical symptoms after EA (15). These findings suggest that EA is effective in treating $80 \%$ of thyroid nodules (with cystic portions $>50 \%$ ), but $20 \%$ of patients who showed incompletely resolved symptoms because of residual solid nodule regions, were effectively treated by RF ablation.

Regarding the factors related to nodule volume reduction, cystic nodules primarily showed a greater decrease in 
size than did mixed or solid nodules at one and three months, but there were no significant differences in volume reduction at six months. These results showed that RF ablation is effective modality, regardless of the proportion of solid component $(2,15)$. Spiezia et al. $(28)$ reported volume reduction was significant for nodules that were initially small, and for nontoxic nodules; however Deandrea et al. (26) showed that volume reduction was not significantly related to nodule autonomy, the amount of heat delivery or initial nodule volume.

Although the short-term results have been promising, marginal re-growth of treated nodules from the nodule margin has been proposed (25) (Fig. 9). Technically complete ablation of nodule margins is not easy, because critical structures are located adjacent to nodule margins
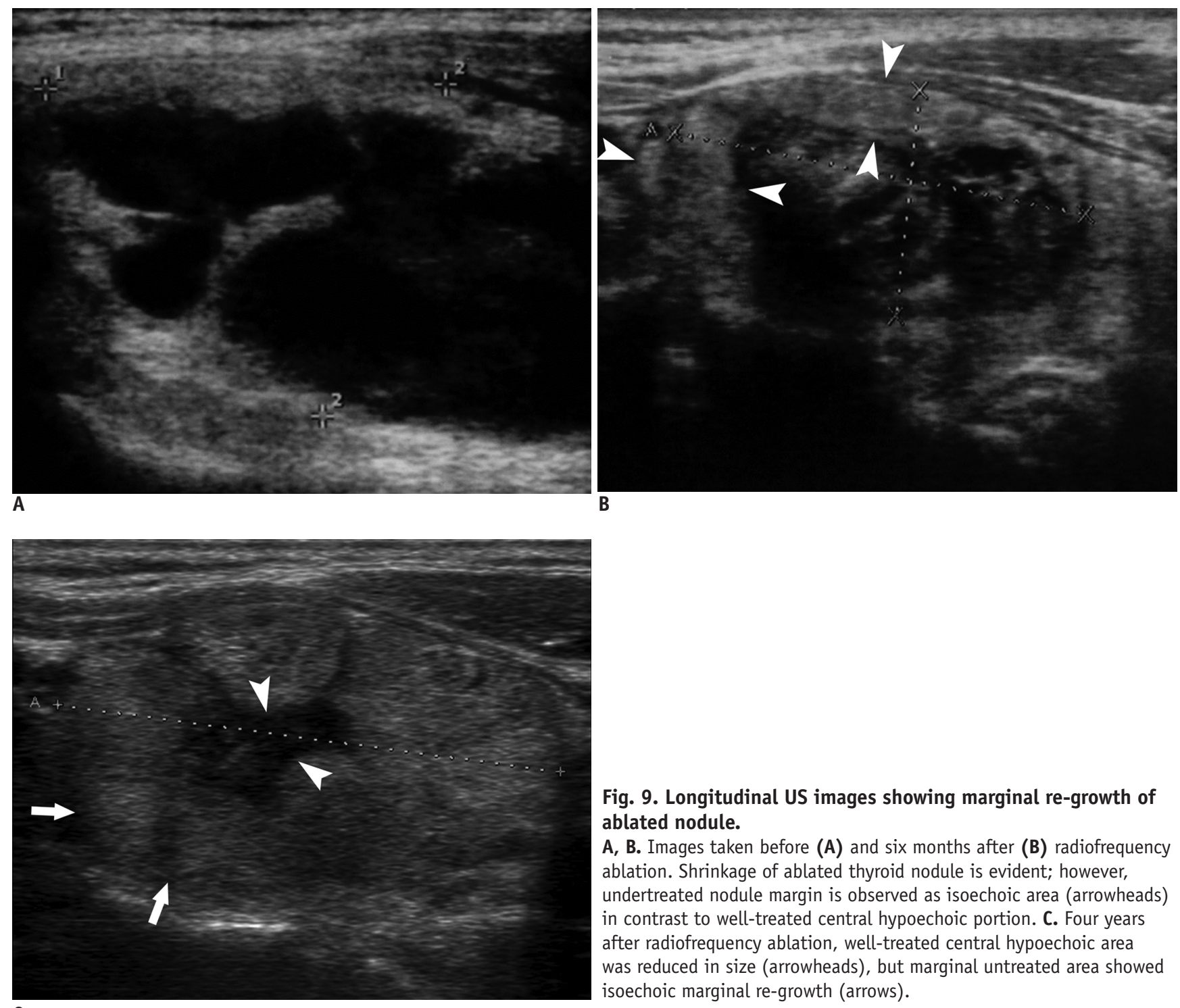

Fig. 9. Longitudinal US images showing marginal re-growth of ablated nodule.

A, B. Images taken before (A) and six months after (B) radiofrequency ablation. Shrinkage of ablated thyroid nodule is evident; however, undertreated nodule margin is observed as isoechoic area (arrowheads) in contrast to well-treated central hypoechoic portion. C. Four years after radiofrequency ablation, well-treated central hypoechoic area was reduced in size (arrowheads), but marginal untreated area showed isoechoic marginal re-growth (arrows). 
common symptom experienced during the procedure. Most of the patients complain of various degrees of pain in the neck and/or radiating to the head, ear, shoulders, chest, back, or teeth. However pain decreases rapidly when the generator output is reduced or turned off (2). Voice change has been reported in four patients, with three showing complete recovery within three months and the fourth patient being lost to follow-up $(2,29)$. One patient with AFTN developed subclinical hypothyroidism at 12 months. However, any association of hypothyroidism with RF ablation was unclear
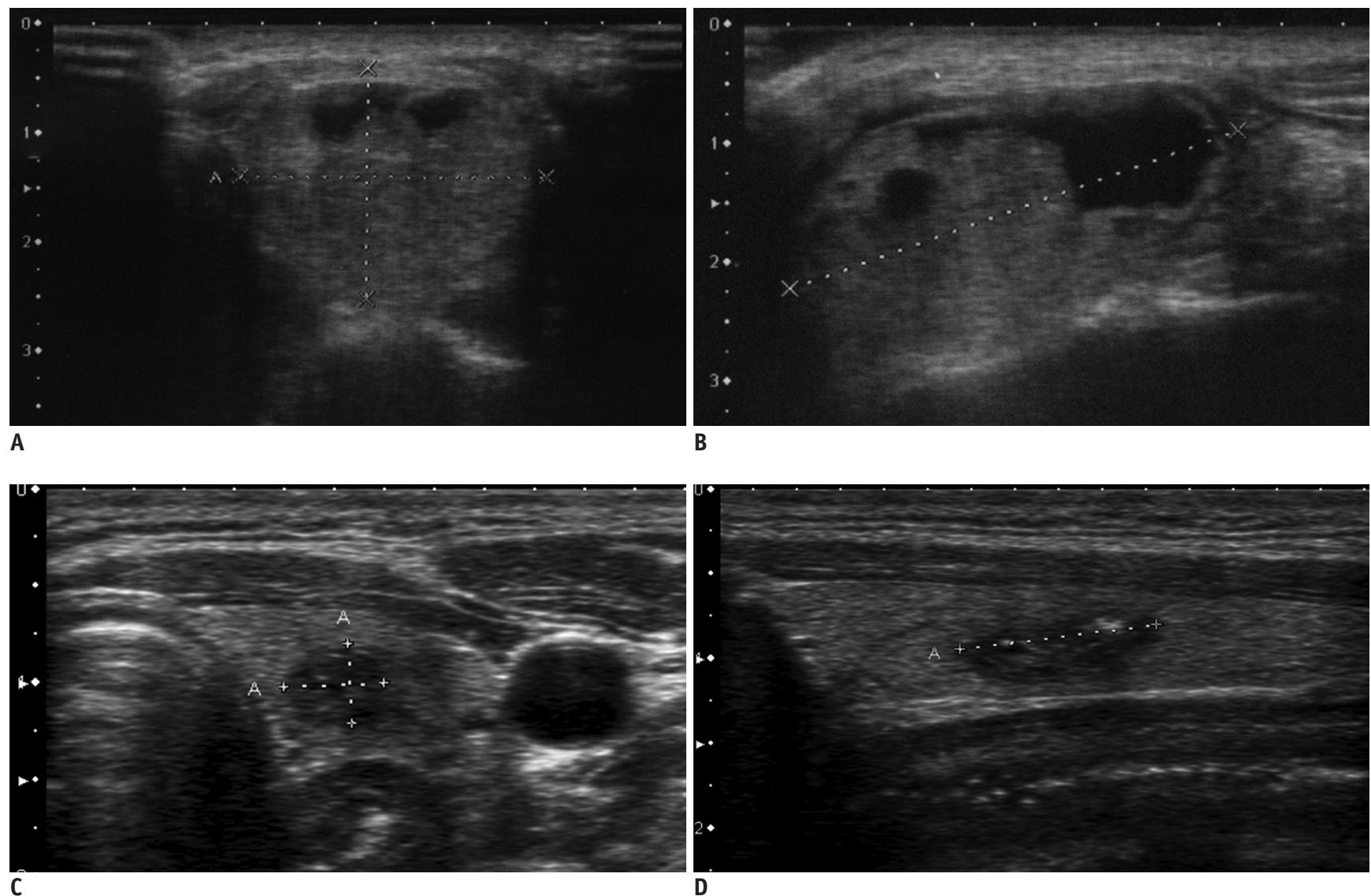

Fig. 10. Transverse and longitudinal US images showing marked shrinkage of ablated nodule.

Images obtained before (A, B) and 54 months after (C, D) radiofrequency ablation, showing that ablated thyroid nodule had decreased markedly in size; only small scar-like lesion remained.

Table 3. Complications Associated with Radiofrequency Ablation of Thyroid Nodules

\begin{tabular}{|c|c|c|c|c|c|c|c|c|}
\hline & $\begin{array}{l}\text { Kim et al., } \\
2006 \text { (29) }\end{array}$ & $\begin{array}{c}\text { Jeong et al., } \\
2008 \text { (2) }\end{array}$ & $\begin{array}{l}\text { Deandrea } \\
\text { et al., } \\
2008(26)\end{array}$ & $\begin{array}{l}\text { Spiezia et al., } \\
2009 \text { (28) }\end{array}$ & $\begin{array}{c}\text { Baek et al., } \\
2009 \text { (25) }\end{array}$ & $\begin{array}{c}\text { Baek et al., } \\
2010 \text { (24) }\end{array}$ & $\begin{array}{l}\text { Lee et al., } \\
2010 \text { (15) }\end{array}$ & Total \\
\hline Number of patients & 30 & 236 & 31 & 94 & 9 & 15 & 27 & 442 \\
\hline Hematoma & 1 & 5 & - & - & - & - & 1 & 7 \\
\hline Skin burn & 1 & - & - & - & - & - & - & 1 \\
\hline Pain & 1 & 13 & Few & 13 & - & - & - & 27 \\
\hline Elevation of fT4 level & 3 & - & - & - & - & - & - & 3 \\
\hline Decreased TSH level & - & 3 & - & - & - & - & - & 3 \\
\hline Hypothyroidism & - & - & - & - & 1 & - & - & 1 \\
\hline Edema & - & - & 3 & - & - & - & - & 3 \\
\hline Fever & - & - & - & 5 & - & - & - & 5 \\
\hline Voice change & 1 & 3 & - & - & - & - & - & 1 \\
\hline
\end{tabular}

Note. - fT $4=$ free T4, TSH = thyrotrophin 
because the patient showed persistent elevation of serum anti-thyroid peroxidase antibody both before and after RF ablation (25). Thyrotoxicosis, as diagnosed by elevated free T4 and decreased TSH concentrations, has been reported in six patients on the day after RF ablation (2, 29). Thyrotoxicosis may be caused by the release of thyroid hormone from thyroid follicles, because of thermal and/ or mechanical injury to the normal thyroid gland. None of the six patients showed any thyrotoxic symptoms, and the levels of free T4 and TSH became normal at one month. Skin burns may occur at the sites of electrode insertion and ground attachment. To date, only first-degree burns have been reported at the electrode insertion site; such burns, however, were self-limiting, without sequela (29). The ground pads act as dispersion electrodes in the RF circuit, and skin burns at pad attachment sites have been reported in patients treated with liver tumors (37). However, the risk of ground pad burn during thyroid RF ablation is not reported yet, because the RF power is much lower than what is employed in liver tumors. Although hematoma, edema, and fever are usually self-limiting, medications may reduce patient symptoms $(2,26,28)$. Hematoma is usually caused by mechanical injury to the vessels around the thyroid gland or in the thyroid nodule. When a large hematoma develops, RF procedure should be delayed for 1-2 weeks. Although large vessels such as the carotid artery and jugular vein can be mechanically damaged by the electrode, the vessels are resistant to thermal injury because of perfusionmediated tissue cooling (21). As thyroid nodules located in the isthmus are very close to the trachea, heat propagation to the trachea is common. This may induce coughing, and ablation should be stopped. To date, permanent tracheal injury has not been reported.

Although fatal complications have not been observed, procedure-related deaths, esophageal perforation, tracheal injury, infection, abscess formation, and permanent voice change are possible complications. These complications could be minimized by improvements in knowledge and by the study of complication-prevention techniques. Several technical tips have been suggested in a recent consensus meeting of the Korean Society of Thyroid Radiology. For example, use of the trans-isthmic approach method and the moving shot technique may reduce complications. Injuries to the recurrent laryngeal nerve and esophagus may be minimized by undertreating the danger triangle (Fig. 6). In addition, esophageal injury may be prevented by asking the patient to swallow cold water during ablation. As suggested by reports on the RF ablation of liver tumors, the relatively fixed colon seems to be at a greater risk for perforation than is the small intestine $(37,38)$. Additional risk factors for bowel injury include prior abdominal surgery and chronic cholecystitis in the region adjacent to the tumor, which are conditions leading to fibrotic adhesions between the bowel and liver tumors (38). The swallowing of cold water during ablation induces esophageal peristalsis, while cooling of the esophagus may reduce thermal damage to the esophagus. During the treatment of thyroid nodules lying just beneath the skin, frequent application of ice bags can prevent skin burn. Unsuccessful attempts have been made to inject saline between critical structures and nodules in order to avoid thermal damage. Because of the longitudinal arrangement of the neck muscles and fascias, injected saline spread rapidly along the muscle plane (39).

\section{Laser Ablation}

\section{Principles of Percutaneous Laser Ablation}

Laser is an acronym for Light Amplified Stimulated Emission of Radiation. Laser technology directs collimated, monochromatic, coherent, and powerful light energy to a well-delimited area of tissue in a predictable, precise, and controlled manner (40). A number of laser sources and wavelengths are currently available. Tissue is destroyed primarily (to about $80 \%$ in extent) by energy absorption. Cell death may continue for up to 72 hours after a procedure

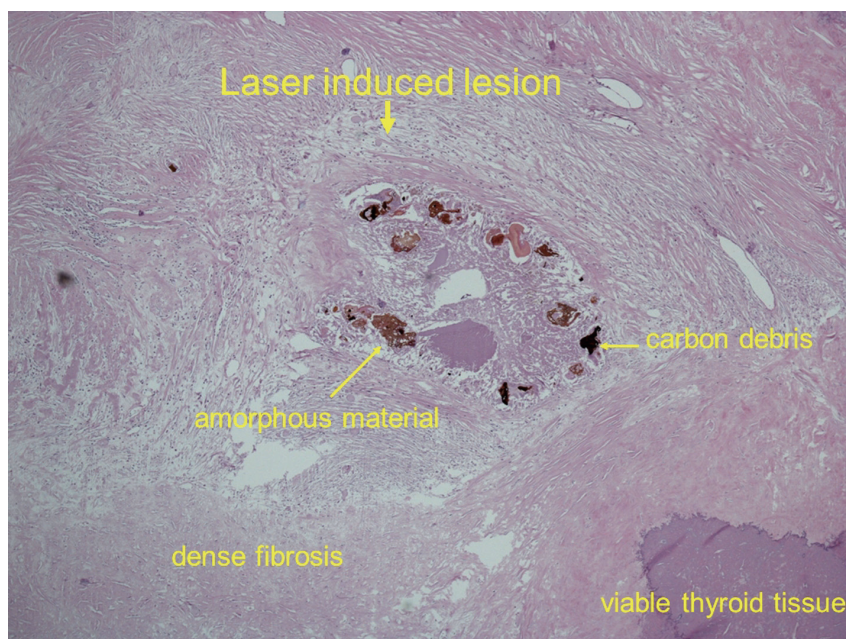

Fig. 11. Microscopic changes occurring in benign thyroid nodule resected two years after laser ablation. Ablation zone is surrounded by peripheral rim of dense fibrous tissue. Destroyed area is represented by amorphous material, carbon debris, macrophages and/or multinucleated giant cells, and lymphocytes, with no thyroid cells. Viable tissue is visible at periphery (lower right corner), and is separated by fibrous tissue from ablation zone. 
because of coagulation of microvessels and ischemic injury (41). Microscopically, the coagulation zone is surrounded by a rim of dense fibrotic tissue that separates necrotic from viable tissue $(40,42-44)$ (Fig. 11). Using a bare tip, near-spherical lesions with a maximum diameter ranging from 12-16 mm can be produced (45). Lesion size can be increased by simultaneous deployment of multiple fibers in an array around the tumor (45). In vitro studies have shown that simultaneous treatment with four fibers separated by 1.0-2.0 $\mathrm{cm}$ produce lesions that are 11-fold larger than are those created using a single fiber; the lesion cylinder was $4.0 \mathrm{~cm}$ in diameter and $3 \mathrm{~cm}$ in height (45). An important practical advantage compared to other thermal sources is that the thin and flexible laser fibers of LA make it possible to reach tumors both easily and safely (46).

The 2010 thyroid nodule guidelines of the American Association of Clinical Endocrinologists/Associazione Medici Endocrinologi (Italian Association of Clinical Endocrinologists)/European Thyroid Association (AACEAME-ETA) are the first to recommend percutaneous LA as a possible choice for the treatment of benign thyroid nodules (47). In the time since the introduction of PLA for thyroid tissue ablation in $2000(48)$, several studies have assessed its effects on thyroid cold $(3,6,7)$, cystic (49), and hot nodules $(7,50,51)$; the studies included controlled trials $(5,52,53)$. All reports found that the new technique was effective and safe. Valcavi and Pacella have practiced LA in patients with benign thyroid cold nodules in Reggio Emilia, Italy, since $2002(7,46,54,55)$.

\section{Inclusion Criteria}

At present, the most important indication for the LA procedure in the thyroid gland is reduction of benign cold thyroid nodules in patients with local pressure symptoms, cosmetic complaints, or who refuse or are poor candidates for surgery. These indications are supported by the data of many scientifically robust studies, including controlled trials featuring homogeneous groups of patients, and investigations of dose-response relationships $(5,52,53)$. Recent study results (55), in agreement with published data $(5,7,56)$, suggest that thermal ablation is appropriate for the debulking of large AFTNs or other unresectable masses.

\section{Technique and Procedure}

Percutaneous LA is an outpatient procedure performed on fasting subjects. The flat-tip method (48) is based on the insertion of a $300 \mu \mathrm{m}$-diameter plane-cut optic fiber through the sheath of a 21-gauge Chiba needle, with 5 $\mathrm{mm}$ of the bare fiber being in direct contact with thyroid tissue. Fiber locks avoid exposure of the tip of the fiber within the lesion beyond an appropriate length. Multiple fibers are inserted into the thyroid gland, forming a shape matching the ellipsoid of most thyroid nodules (54). The goal of our procedure is to achieve a maximum ablation volume in a single LA outpatient session. From 20022008, Valcavi and Pacella have used an Nd:YAG laser with an emission wavelength of $1064 \mu \mathrm{m}$, equipped with a four-source beam splitter (DEKA M.E.L.A., Florence, Italy). Valcavi and Pacella also used an ultrasound device and a $1,064 \mu \mathrm{m}$ diode laser unit (Echolaser $\times 4^{\circledR}$, Elesta, Florence, Italy), which permitted the use of a maximum of four laser sources, each with an individual energy emission setting and independent activation. A patient is placed on an operating table in the supine position with the neck hyperextended. The operator, seated behind the patient's head, watches real-time US images on an auxiliary monitor placed on a tower at the patient's feet. The US equipment is operated by an assistant sitting to the right of the patient. Light conscious sedation is obtained using intravenous midazolam (2-5 mg), which was administered in fractionated boli. Emergency care drugs and equipment, including a defibrillator, are located in the interventional suite. Although an anesthesiologist is not present during LA sessions, it is recommended that PLA be performed in a healthcare facility in which an anesthesiologist and surgeon are available. Local anesthesia consists of $2 \%$ subcutaneous Lidocaine, followed by subcapsular infiltration of Lidocaine (2-5 mL) under US guidance. One-to-four 21-gauge Chiba needles are manually placed along the longitudinal, cranio-

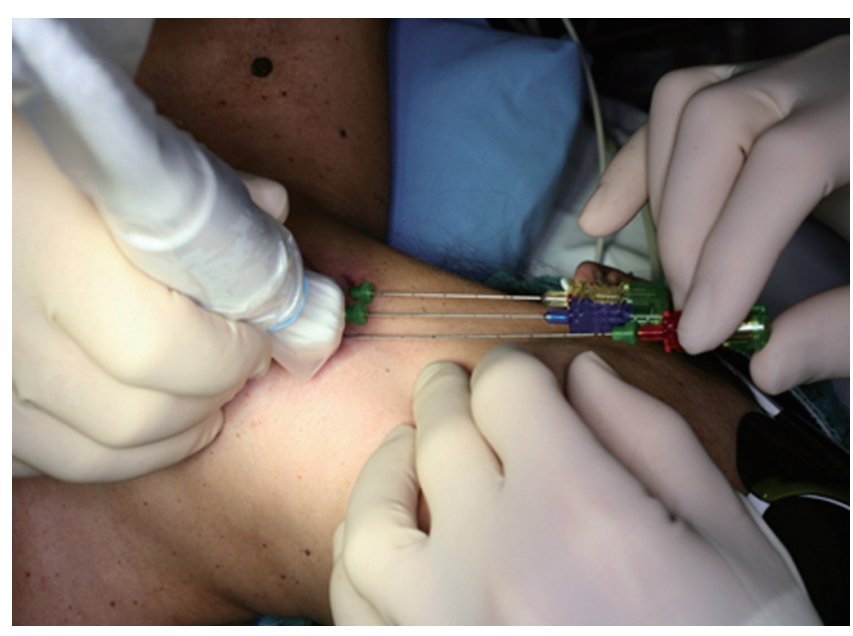

Fig. 12. Placement of Chiba G21 needles along cranio-caudal major nodule axis; needles are separated by $10 \mathrm{~mm}$. 
caudal, and major nodule axes, separated by $10 \mathrm{~mm}$, and matching the nodule anatomy as closely as possible (Fig. 12). Multiplanar US images on axial and longitudinal scans are obtained by the assistant, through laser illumination, allowing for real-time visual control of each source. The initial energy is delivered at 1,200-1,800 Joules per fiber with an output power of 2-4 W, starting at $1.0 \mathrm{~cm}$ from the bottom of the lesion. A highly echogenic region, resulting from tissue heating and vaporization, gradually increases over time, until coalescence between fibers is observed (Fig. 13). By upwards needle/fiber pull-backs in $1.0 \mathrm{~cm}$ increments, additional doses of laser energy are administered at each step until the needles/fibers are $5 \mathrm{~mm}$ away from the cranial portion of the nodule. While nodules as small as $5 \mathrm{~mm}$ in diameter may be ablated using a single optic fiber, nodules up to $40-50 \mathrm{~mm}$ in width, $30-35 \mathrm{~mm}$ in thickness, and 50-70 mm in length (i.e., up to $30-60 \mathrm{~mL}$ in volume) may be treated in a single LA session by combining multiple fiber placement, needle/fiber pullback, and use of high energy. The number of fibers, number of pullbacks, and total energy delivered, are tailored to nodule volume and to the ellipsoidal shape that characterizes such nodules. The duration of laser illumination ranges from 6-30 minutes, depending on nodule size. Light irradiation is continuous, being suspended for fiber repositioning only in the event of severe pain, cough, or appearance of other side-effects (54).
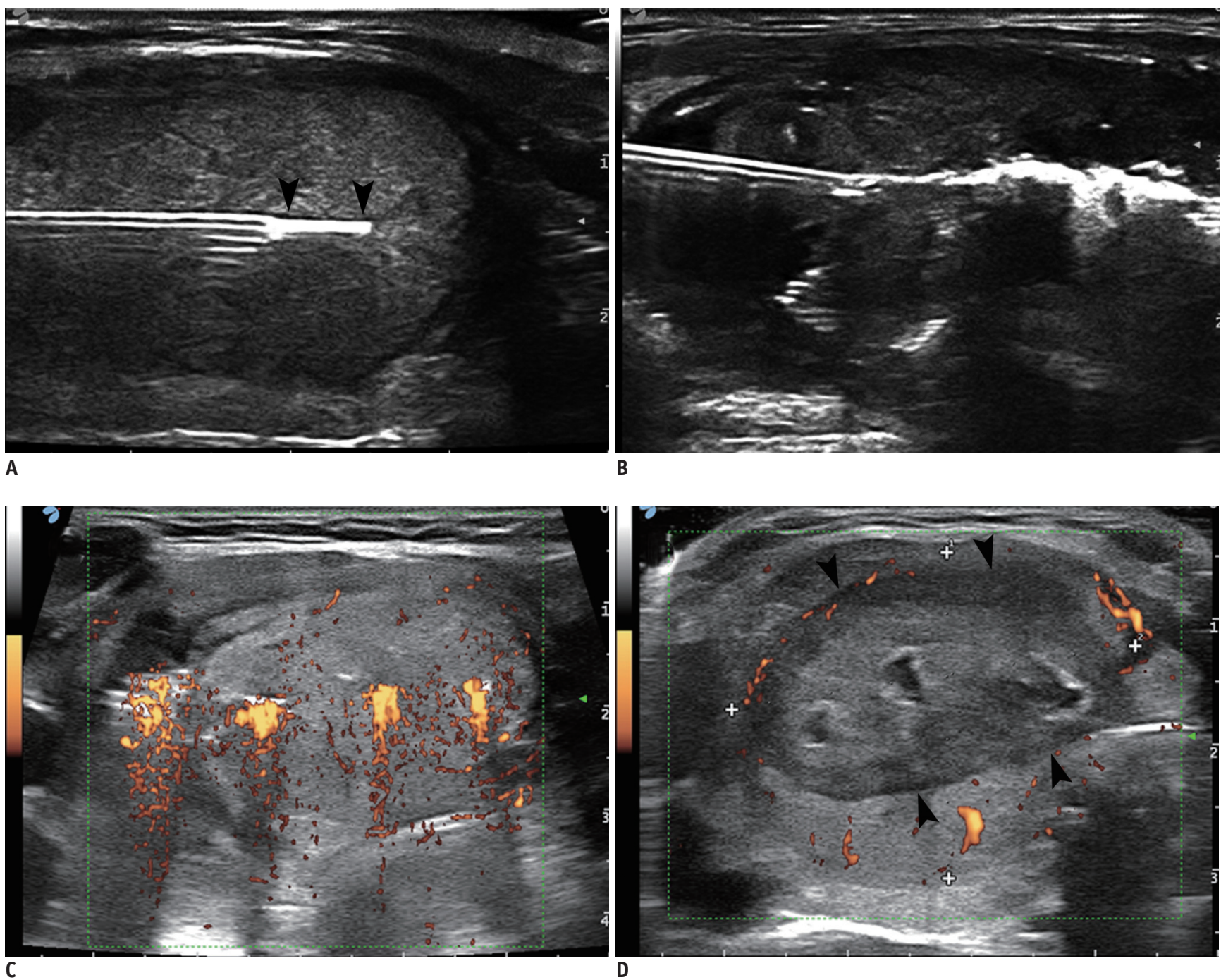

Fig. 13. Percutaneous laser ablation procedure using three sources.

A. Longitudinal US images of needle typically placed within thyroid nodule along cranio-caudal axis. Fiber is exposed to depth about $5 \mathrm{~mm}$ beyond tip of needle (arrowheads). B. Highly echogenic area resulting from tissue heating and vaporization is observed during laser firing. C. Color Doppler US images obtained by laser illumination. D. Final ablation: coalescence between fibers creates single lesion matching anatomy of thyroid nodule. Laser marks are seen as anechoic spots (cavitation caused by tissue vaporization) surrounded by hyperechoic rims (charring). Coagulation zone is hypoechoic parenchyma (arrowheads) separated by rim from viable tissue. 


\section{Follow-Up Evaluation}

Immediately after performing the LA procedure, each patient receives prednisone intravenously, in a $20 \mathrm{mg}$ bolus, and an ice pack is applied to the neck using mild pressure. The patient is next taken to the recovery room and kept under observation for about 2 hours. Before leaving the hospital, each patient undergoes US examination. The day after the LA procedure, all patients are commenced on tapered oral prednisone therapy consisting of $25 \mathrm{mg} /$ day for three days, $12.5 \mathrm{mg} /$ day for three days, and $5 \mathrm{mg} /$ day for four days. Oral pump inhibitors are simultaneously administered (lansoprazole, $30 \mathrm{mg}$ ) for the 10 days of oral prednisone therapy.

\section{Clinical Results}

Percutaneous LA has been reported to cause the shrinkage of cold benign thyroid nodules, with volume reductions ranging from $36-82 \%$ of the initial volume. Valcavi and Pacella have evaluated the safety features and effects of LA treatment, delivered via thermal Nd:YAG laser ablation, in 122 patients $(M: F=27: 95$; age, $52.2 \pm 12.3$ years) with benign cold solitary thyroid nodules or with dominant

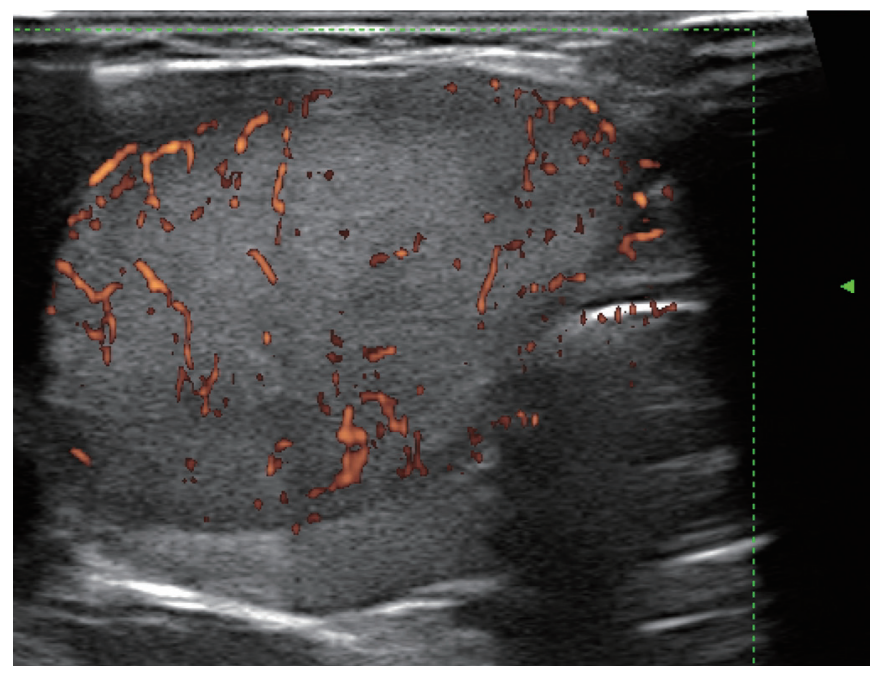

A

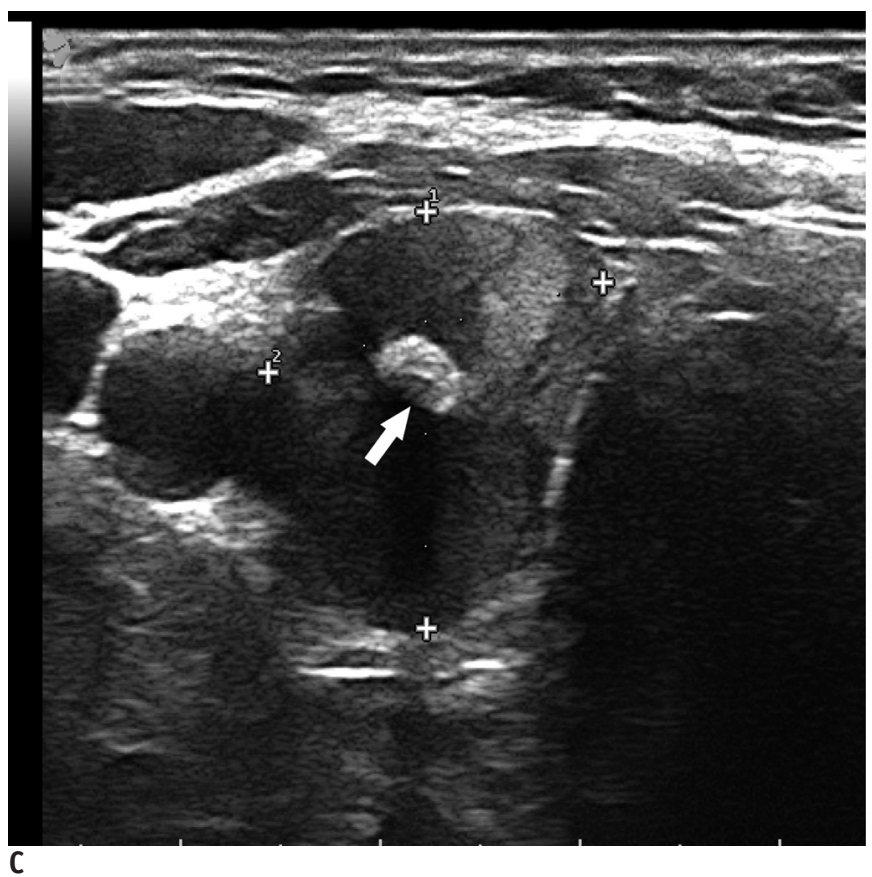

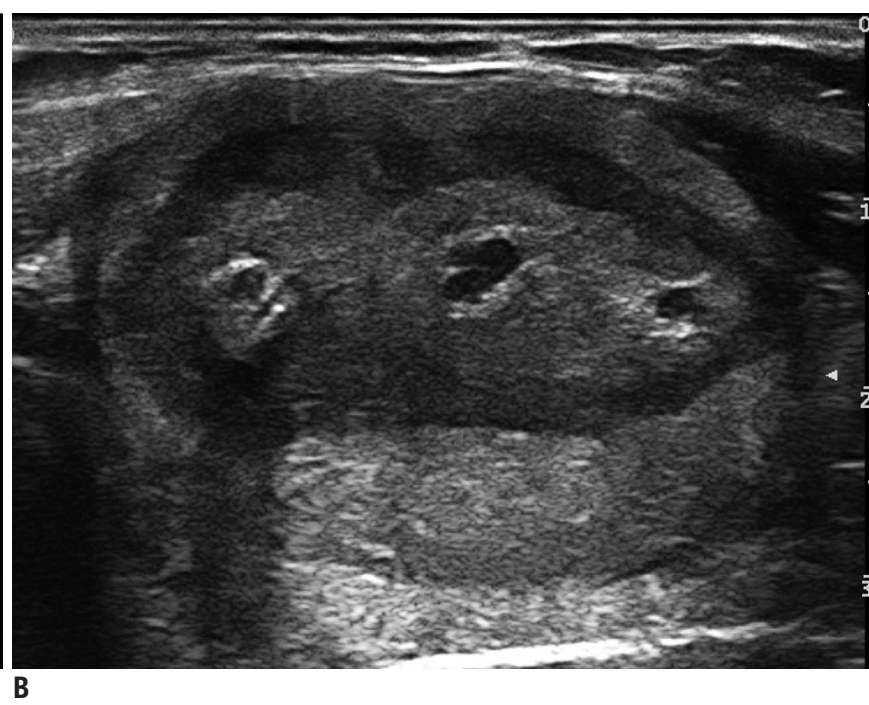

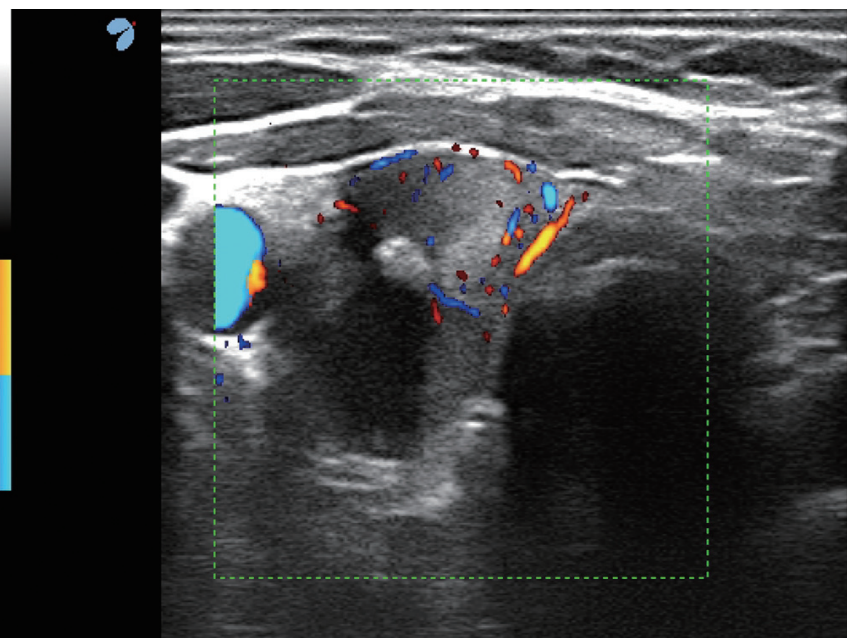

D

Fig. 14. Typical three-fiber laser ablation of compact, cold, benign nodule of right thyroid lobe (volume, $25 \mathrm{~mL}$ ).

Before (A), one day after (B), one year after (C), and three years after (D) percutaneous laser ablation. Nodule shrinkage is usually associated with development of central hyperechoic area caused by tissue scarring (arrow). 
nodules existing within a normo-functioning multinodular goiter (volume range, 2.6-86.4 mL). Three years after LA, mean nodule volume had fallen from $23.1 \pm 21.3 \mathrm{~mL}$ to $12.5 \pm 18.8 \mathrm{~mL}$ ( $48 \pm 33.1 \%$ of initial volume, $p \leq 0.001)$. Moreover, symptoms had improved in 89 patients $(73 \%)$, were unchanged in $28(23 \%)$, and had worsened in only five (4\%). Cosmetic signs had improved in 87 patients (71\%), were unchanged in $29(24 \%)$, and had worsened in six $(5 \%)$. In 11 patients (9\%), nodules re-grew to attain diameters above baseline values (55). Figure 14 shows a representative example of LA treatment of a compact nodule.

\section{Complications}

Only a few complications and side-effects have been reported $(3,5-7,50,52-55)$. Intra-operation pain is usually absent, whereas persistent pain, occurring in $8-40 \%$ of patients, may require additional medication $(3,5-7,52,54$, 55). In Valcavi and Pacella's clinical experience, thus in the treatment of 122 patients who were followed-up for three years, intranodular bleeding during needle placement was controlled by rapid fiber insertion and laser illumination, and did not result in the abortion of the regular ablation procedure. Valcavi and Pacella have found that $2 \%$ of our patients experienced thyroid pericapsular bleeding, as shown by development of an asymptomatic hypoechoic layer surrounding the thyroid lobe, but this disappeared in 3-4 weeks (55). Vagal symptoms with bradycardia occurred in $2 \%$ of patients during needle placement, and $2 \%$ of patients complained of cough during laser irradiation. In the latter patients, the fiber closest to the trachea were simply pulled back and the LA procedure was completed. To date, no patient under our care has ever had intra/perioperative dysphonia, although $2 \%$ of patients have complained of voice change 12-24 hours after the LA procedure; indirect laryngoscopy revealed reduced vocal cord motility. An additional course of corticosteroids was administered, with complete recovery within 1-2 months. Pseudocyst transformation occurred in $5 \%$ of patients, exemplified by rapid development of painful neck swelling 2-4 weeks after LA; such patients underwent drainage using a 16-18 gauge Chiba needle. In $3 \%$ of our 122 patients, fluid leakage into the neck muscle fascia was observed, but such subfascial effusion disappeared within 3-4 months and no permanent consequences were apparent. No patient treated by us to date has required surgical drainage. Rare side-effects include skin burn $(0.3 \%)$ and transient stridor $(0.3 \%)$. In the first six months after $\mathrm{LA}, 3 \%$ of our patients developed thyroid dysfunction, either hyper- (1\%) or hypothyroidism (1\%). It is unknown whether these symptoms reflected natural disease courses or were laser-induced (55). It should be noted that all complications discussed were experienced by patients treated with the Nd:YAG laser, including those treated by physicians at the beginning of their learning curves (55). Using the procedure described above and the Ecolaser $X 4^{\circledR}$, the side-effects have been notably milder.

\section{Comparison of Radiofrequency Ablation and Laser} Ablation

The efficacy of RF ablation appears to be slightly superior to that of PLA, and the adverse effects somewhat fewer (Table 2) (57). These slight but useful benefits are attributable to the use of the moving shot technique and an internal cooling system. It should be noted, however, that RF series included nodules which were smaller and had a greater cystic component than nodules treated with LA. Furthermore, LA studies have been carried out with respect to controlled trials, use of homogeneous patient groups, and investigations of dose-response relationships. Thus, the accumulated evidence of LA is scientifically more robust than that of RF ablation (57).

\section{CONCLUSION}

Two thermal ablation therapies, RF ablation and LA, are effective and safe non-surgical methods for treatment of benign thyroid nodules. To formally establish thermal therapies as alternatives to surgery, it is important to maximize efficacy and minimize complications. Efficacy may be optimized by complete ablation of the entire tumor margin, which is essential to both prevent marginal regrowth at long term follow-up and to effectively reduce thyroid nodule volume. To minimize complications, it is important to consider the broad spectrum of possible complications, and the preventative techniques available. Also, before routine use of such a procedure can be recommended, prospective randomized studies and/or controlled trials on RF versus LA must be conducted to establish eligibility criteria, to determine long-term efficacy, and to assess safety, cost/benefit balance, and quality-of-life.

\section{REFERENCES}

1. Mazzaferri EL. Management of a solitary thyroid nodule. $N$ 
Engl J Med 1993;328:553-559

2. Jeong WK, Baek JH, Rhim H, Kim YS, Kwak MS, Jeong HJ, et al. Radiofrequency ablation of benign thyroid nodules: safety and imaging follow-up in 236 patients. Eur Radiol 2008;18:1244-1250

3. Papini E, Guglielmi R, Bizzarri G, Pacella CM. Ultrasoundguided laser thermal ablation for treatment of benign thyroid nodules. Endocr Pract 2004;10:276-283

4. Shemen LJ, Strong EW. Complications after total thyroidectomy. Otolaryngol Head Neck Surg 1989;101:472-475

5. Papini E, Guglielmi R, Bizzarri G, Graziano F, Bianchini A, Brufani $C$, et al. Treatment of benign cold thyroid nodules: a randomized clinical trial of percutaneous laser ablation versus levothyroxine therapy or follow-up. Thyroid 2007;17:229-235

6. Dossing H, Bennedbaek FN, Karstrup S, Hegedus L. Benign solitary solid cold thyroid nodules: US-guided interstitial laser photocoagulation--initial experience. Radiology 2002;225:5357

7. Pacella CM, Bizzarri G, Spiezia S, Bianchini A, Guglielmi R, Crescenzi $A$, et al. Thyroid tissue: US-guided percutaneous laser thermal ablation. Radiology 2004;232:272-280

8. Papini E, Pacella CM, Verde G. Percutaneous ethanol injection (PEI): what is its role in the treatment of benign thyroid nodules? Thyroid 1995;5:147-150

9. Spiezia S, Vitale G, Di Somma C, Pio Assanti A, Ciccarelli A, Lombardi $G$, et al. Ultrasound-guided laser thermal ablation in the treatment of autonomous hyperfunctioning thyroid nodules and compressive nontoxic nodular goiter. Thyroid 2003;13:941-947

10. Valcavi R, Frasoldati A. Ultrasound-guided percutaneous ethanol injection therapy in thyroid cystic nodules. Endocr Pract 2004;10:269-275

11. Sung JY, Baek JH, Kim YS, Jeong HJ, Kwak MS, Lee D, et al. One-step ethanol ablation of viscous cystic thyroid nodules. AJR Am J Roentgenol 2008;191:1730-1733

12. Yasuda K, Ozaki 0, Sugino K, Yamashita T, Toshima K, Ito K, et al. Treatment of cystic lesions of the thyroid by ethanol instillation. World J Surg 1992;16:958-961

13. Zingrillo M, Torlontano M, Chiarella R, Ghiggi MR, Nirchio V, Bisceglia $M$, et al. Percutaneous ethanol injection may be a definitive treatment for symptomatic thyroid cystic nodules not treatable by surgery: five-year follow-up study. Thyroid 1999;9:763-767

14. Kim JH, Lee HK, Lee JH, Ahn IM, Choi CG. Efficacy of sonographically guided percutaneous ethanol injection for treatment of thyroid cysts versus solid thyroid nodules. AJR Am J Roentgenol 2003;180:1723-1726

15. Lee JH, Kim YS, Lee D, Choi H, Yoo H, Baek JH. Radiofrequency ablation (RFA) of benign thyroid nodules in patients with incompletely resolved clinical problems after ethanol ablation (EA). World J Surg 2010;34:1488-1493

16. Dupuy DE, Goldberg SN. Image-guided radiofrequency tumor ablation: challenges and opportunities--part II. J Vasc Interv Radiol 2001;12:1135-1148

17. Goldberg SN. Radiofrequency tumor ablation: principles and techniques. Eur J Ultrasound 2001;13:129-147

18. Kang TW, Rhim H, Kim EY, Kim YS, Choi D, Lee WJ, et al. Percutaneous radiofrequency ablation for the hepatocellular carcinoma abutting the diaphragm: assessment of safety and therapeutic efficacy. Korean J Radiol 2009;10:34-42

19. Lencioni R, Cioni D, Bartolozzi C. Percutaneous radiofrequency thermal ablation of liver malignancies: techniques, indications, imaging findings, and clinical results. Abdom Imaging 2001;26:345-360

20. Park SH, Yoon SK, Cho JH, Oh JY, Nam KJ, Kwon HJ, et al. Radiofrequency ablation treatment for renal cell carcinoma: early clinical experience. Korean J Radiol 2008;9:340-347

21. Rhim H, Goldberg SN, Dodd GD 3rd, Solbiati L, Lim HK, Tonolini $\mathrm{M}$, et al. Essential techniques for successful radiofrequency thermal ablation of malignant hepatic tumors. Radiographics 2001;21 Spec No:S17-35; discussion S36-19

22. Kanauchi H, Mimura Y, Kaminishi M. Percutaneous radiofrequency ablation of the thyroid guided by ultrasonography. Eur J Surg 2001;167:305-307

23. Baek JH, Jeong HJ, Kim YS, Kwak MS, Lee D. Radiofrequency Ablation for an Autonomously Functioning Thyroid Nodule. Thyroid 2008;18:675-676

24. Baek JH, Kim YS, Lee D, Huh JY, Lee JH. Benign predominantly solid thyroid nodules: prospective study of efficacy of sonographically guided radiofrequency ablation versus control condition. AJR Am J Roentgenol 2010;194:1137-1142

25. Baek JH, Moon WJ, Kim YS, Lee JH, Lee D. Radiofrequency ablation for the treatment of autonomously functioning thyroid nodules. World J Surg 2009;33:1971-1977

26. Deandrea M, Limone $P$, Basso E, Mormile A, Ragazzoni F, Gamarra $E$, et al. US-guided percutaneous radiofrequency thermal ablation for the treatment of solid benign hyperfunctioning or compressive thyroid nodules. Ultrasound Med Biol 2008;34:784-791

27. Spiezia S, Garberoglio R, Di Somma C, Deandrea M, Basso E, Limone PP, et al. Efficacy and safety of radiofrequency thermal ablation in the treatment of thyroid nodules with pressure symptoms in elderly patients. J Am Geriatr Soc 2007;55:14781479

28. Spiezia S, Garberoglio R, Milone F, Ramundo V, Caiazzo C, Assanti AP, et al. Thyroid nodules and related symptoms are stably controlled two years after radiofrequency thermal ablation. Thyroid 2009;19:219-225

29. Kim YS, Rhim H, Tae K, Park DW, Kim ST. Radiofrequency ablation of benign cold thyroid nodules: initial clinical experience. Thyroid 2006;16:361-367

30. Dupuy DE, Monchik JM, Decrea C, Pisharodi L. Radiofrequency ablation of regional recurrence from well-differentiated thyroid malignancy. Surgery 2001;130:971-977

31. Monchik JM, Donatini G, Iannuccilli J, Dupuy DE. Radiofrequency ablation and percutaneous ethanol injection treatment for recurrent local and distant well-differentiated thyroid carcinoma. Ann Surg 2006;244:296-304

32. Haemmerich D, Laeseke PF. Thermal tumour ablation: devices, 
clinical applications and future directions. Int $\mathrm{J}$ Hyperthermia 2005;21:755-760

33. Goldberg SN, Gazelle GS, Mueller PR. Thermal ablation therapy for focal malignancy: a unified approach to underlying principles, techniques, and diagnostic imaging guidance. $A J R$ Am J Roentgenol 2000;174:323-331

34. Baek JH, Na DG, Lee JH, Jung SL, Sung JY, Sim J, et al. Korean Society of Thyroid Radiology recommendations for radiofrequency ablation of thyroid nodules. 2009 http:// thyroidimaging. $\mathrm{kr}$

35. Moon WJ, Baek JH, Jung SL, Kim DW, Kim EK, Kim JY, et al. Ultrasonography and the ultrasound-based management of thyroid nodules: consensus statement and recommendations. Korean J Radiol 2011;12:1-14

36. Moon WJ, Jung SL, Lee JH, Na DG, Baek J-H, Lee YH, et al. Benign and malignant thyroid nodules: US differentiation-multicenter retrospective study. Radiology 2008;247:762-770

37. Rhim H, Yoon KH, Lee JM, Cho Y, Cho JS, Kim SH, et al. Major complications after radio-frequency thermal ablation of hepatic tumors: spectrum of imaging findings. Radiographics 2003;23:123-134; discussion 134-126

38. Livraghi T, Solbiati L, Meloni MF, Gazelle GS, Halpern EF, Goldberg SN. Treatment of focal liver tumors with percutaneous radio-frequency ablation: complications encountered in a multicenter study. Radiology 2003;226:441451

39. Baek JH, Kim YS, Sung JY, Choi H, Lee JH. Locoregional control of metastatic well differentiated thyroid cancer in the neck by ultrasonography-guided radiofrequency ablation. AJR Am J Roentgenol 2011;197:W331-W336

40. Dachman AH, McGehee JA, Beam TE, Burris JA, Powell DA. USguided percutaneous laser ablation of liver tissue in a chronic pig model. Radiology 1990;176:129-133

41. Nikfarjam M, Muralidharan V, Malcontenti-Wilson C, Christophi C. Progressive microvascular injury in liver and colorectal liver metastases following laser induced focal hyperthermia therapy. Lasers Surg Med 2005;37:64-73

42. Nolsøe CP, Torp-Pedersen S, Burcharth F, Horn T, Pedersen S, Christensen $\mathrm{NE}$, et al. Interstitial hyperthermia of colorectal liver metastases with a US-guided Nd-YAG laser with a diffuser tip: a pilot clinical study. Radiology 1993;187:333337

43. Pacella CM, Rossi Z, Bizzarri G. Ultrasound-guided percutaneous laser ablation of liver tissue in a rabbit model. Eur Radiol 1993;3:26-32

44. Ritz JP, Lehmann KS, Zurbuchen U, Knappe V, Schumann T, Buhr $\mathrm{HJ}$, et al. Ex vivo and in vivo evaluation of laser-induced thermotherapy for nodular thyroid disease. Lasers Surg Med 2009;:41:479-486

45. Tranberg KG. Percutaneous ablation of liver tumours. Best Pract Res Clin Gastroenterol 2004;18:125-145
46. Pacella CM, Bizzarri G, Francica G, Bianchini A, De Nuntis $S$, Pacella $S$, et al. Percutaneous laser ablation in the treatment of hepatocellular carcinoma with small tumors: analysis of factors affecting the achievement of tumor necrosis. J Vasc Interv Radiol 2005;16:1447-1457

47. Gharib H, Papini E, Paschke R, Duick DS, Valcavi R, Hegedus $\mathrm{L}$, et al. American Association of Clinical Endocrinologists, Associazione Medici Endocrinologi, and EuropeanThyroid Association Medical Guidelines for Clinical Practice for the Diagnosis and Management of Thyroid Nodules. Endocr Pract 2010;16 Suppl 1:1-43

48. Pacella CM, Bizzarri G, Guglielmi R, Anelli V, Bianchini A, Crescenzi A, et al. Thyroid tissue: US-guided percutaneous interstitial laser ablation-a feasibility study. Radiology 2000;217:673-677

49. Dossing H, Bennedbaek FN, Hegedus L. Beneficial effect of combined aspiration and interstitial laser therapy in patients with benign cystic thyroid nodules: a pilot study. $\mathrm{Br} \mathrm{J}$ Radiol 2006;79:943-947

50. Cakir B, Topaloglu 0, Gul K, Agac T, Aydin C, Dirikoc A, et al. Effects of percutaneous laser ablation treatment in benign solitary thyroid nodules on nodule volume, thyroglobulin and anti-thyroglobulin levels, and cytopathology of nodule in $1 \mathrm{yr}$ follow-up. J Endocrinol Invest 2006;29:876-884

51. Dossing H, Bennedbaek FN, Hegedus L. Ultrasound-guided interstitial laser photocoagulation of an autonomous thyroid nodule: the introduction of a novel alternative. Thyroid 2003;13:885-888

52. Dossing H, Bennedbaek FN, Hegedus L. Effect of ultrasoundguided interstitial laser photocoagulation on benign solitary solid cold thyroid nodules - a randomised study. Eur J Endocrinol 2005;152:341-345

53. Gambelunghe G, Fatone C, Ranchelli A, Fanelli C, Lucidi P, Cavaliere $\mathrm{A}$, et al. A randomized controlled trial to evaluate the efficacy of ultrasound-guided laser photocoagulation for treatment of benign thyroid nodules. $J$ Endocrinol Invest 2006;29:RC23-26

54. Valcavi R, Bertani A, Pesenti ML, Al Jandali Rifa' L, Frasoldati $A$, Formisano $D$, et al. Laser and radiofrequency ablation procedures. In: Baskin HJ, Duick DS, Levine RA, eds. Thyroid ultrasound and ultrasound-guided FNA biopsy. New York: Springer, 2008:191-218

55. Valcavi R, Riganti F, Bertani A, Formisano D, Pacella CM. Percutaneous laser ablation of cold benign thyroid nodules: a 3 -year follow-up study in 122 patients. Thyroid 2010;20:12531261

56. Papini E, Bizzarri G, Pacella CM. Percutaneous laser ablation of benign and malignant thyroid nodules. Curr Opin Endocrinol Diabetes Obes 2008;15:434-439

57. Hegedus L. Therapy: a new nonsurgical therapy option for benign thyroid nodules? Nat Rev Endocrinol 2009;5:476-478 